\title{
Practical aspects of differential ventilation with selective peep in acute respiratory failure
}

\author{
Göran Hedenstierna, Svante Baehrendtz, Marek Darowski and Claes Frostell \\ Department of Clinical Physiology, Huddinge University Hospital, 14186 Huddinge, Sweden; Department of \\ Medicine, South Hospital and Department of Anaesthesia, Danderyd Hospital, Stockholm, Sweden
}

Keywords: anaesthesia, acute respiratory failure, differential ventilation, perfusion, PEEP

\begin{abstract}
Hypoxaemia in association with acute respiratory failure continues to be a severe problem in some intensive care patients. Among strategies proposed, we want to focus attention on differential ventilation with selective PEEP, administered in the lateral position. This ventilation technique has proved successful in the treatment of refractory hypoxaemia due to severe bilateral lung disease.

The rationale of this concept is briefly presented in this paper, where the main emphasis is laid on the practical aspects of its clinical application. Two case reports are included as examples of our experiences.
\end{abstract}

\section{Introduction}

The method of ventilating each lung separately (independent or differential ventilation), with or without application of positive end expiratory pressure (PEEP) to one or both lungs has been used in selected cases of severe unilateral or non-homogeneous lung disease in order to improve the matching of ventilation and perfusion and thereby to enhance gas exchange $(1,2)$. It has also become a valuable tool during thoracic surgery, in the form of one-lung ventilation, facilitating intervention in the non-ventilated lung $(3,4)$. Recently, a ventilation concept based on differential ventilation and selective PEEP with the patient in the lateral position has been shown to improve the gas exchange in bilateral lung disease, involving both lungs to more or less equal extent $(5,6,7)$. In the following, the rationale of conducting differential ventilation in unilateral as well as in bilateral lung disease is analysed, the technical procedures are discussed and two cases of bilateral lung disease treated with differential ventilation are presented.

\section{Ventilation and perfusion in unilateral lung dissease}

If a pathological abnormality is unequally distributed between the two lungs, resulting in lower compliance or higher airway resistance in the more seriously diseased lung, the less diseased lung will receive a larger fraction of the tidal volume. In the event that perfusion is less affected by the disease, with no or little diversion of blood flow away from the affected lung, ventilation-perfusion mismatching will ensue. Moreover, this imbalance may be worsened by the application of general PEEP which may increase the compliance and thus the ventilaton of the less affected or unaffected lung. Adverse effects of general PEEP in unilateral lung disease have also been reported in the literature (8, 1). Under such circumstances it would seem rational to direct ventilation to the lung separately, in order to improve the matching between ventilation and perfusion.

However, other means of improving gas exchange in unilateral lung disease may be con- 
sidered. Placing the patient in the lateral position with the sick lung up reduces the perfusion of that lung in which the gas exchange is impaired. The more healthy lung will be in the dependent position and thus will receive the gross part of the perfusion. This has been shown to improve arterial oxygenation $(9,10)$. The possibility of gravitational migration of infectious secretions down to the healthier lung is a conceivable drawback to the lateral posture.

Another way of directing the perfusion away from the sick lung is to insert a ballloon catheter into the main pulmonary artery of that lung and then to infate the balloon in order to occlude the vessel (11). This might be a valuable form of treatment in some individual, severe cases, but the experiences are very limited.

\section{Ventilation and perfusion in bilateral lung disease}

Acute respiratory failure (ARF) appears to be accompanied by a considerable decrease in the resting lung volume - the functional residual capacity (FRC). Thus, Katz et al. (12) reported a fall in FRC to $55 \%$ of the predicted value in the supine position, corresponding to a 1.3 litre reduction, in patients suffering from ARF after massive trauma, major surgery, or metabolic or infectious disease. It has been shown in normal subjects that a deep expiration causes dependent airways to close, impeding ventilation in lower lung regions (13). Pontoppidan and co-workers (14) proposed that the fall in FRC in ARF promotes airway closure. As far as we know no studies on airway closure in patients with ARF have been reported, but considerable impediment of dependent-lung ventilation has been demonstrated in various kinds of ARF in patients requiring ventilator treatment $(6,7)$. This may be attributed to closure of dependent airways and/or alveolar collapse. Thus, ventilation is preferentially distributed to non-dependent lung regions. Perfusion, on the other hand, is distributed mainly to dependent lung regions, even in the healthy subject because of gravitational forces (15). In the patient with ARF, high airway and alveolar pressures are often required for adeqauate ventila- tion and this will force perfusion further down the lung. Ventilation-perfusion mismatching $(\dot{V} / \dot{Q}$ inequality) will ensue, impeding gas exchange and arterial oxygenation.

\section{Selective PEEP and differential ventilation}

The application of general PEEP has been shown to improve the oxygenation of blood in many cases of ARF $(16,17)$. General PEEP increases the ventilation of dependent lung regions in patients during anaesthesia (18) and it is thus reasonable to assume that PEEP opens up collapsed dependent airways and alveoli. However, general PEEP also has its drawbacks. First, the increased intrathoracic mean pressure reduces cardiac output by impeding venous return (19) and a concomitant increase in alveolar pressure forces pulmonary blood flow to dependent regions (20). Secondly, the effect of PEEP on the regional lung volume is unfavourably distributed, dependent lung tissue becoming less expanded than non-dependent tissue (21). It may thus be concluded that PEEP does not provide the physiological basis for optimal matching between ventilation and perfusion, and it may even cause lung damage (22). With the human subject in the lateral position, the anatomical configuration of the bronchial tree permits a subdivision of ventilation to two vertically different lung compartments, i.e. the dependent and the non-dependent lung. Ventilaton may thus be vertically distributed in proportion to the assumed distribution of perfusion (differential ventilation), more gas being delivered to the dependent and less to the non-dependent lung than would have been the case with conventional ventilation. By applying PEEP to the dependent lung alone (selective PEEP), distribution of inspired gas to lower regions within that lung can be ensured. Because of the lower overall intrathoracic pressure and the lower degree of lung expansion, interference with total pulmonary blood flow and the danger of barotrauma should be less than with general PEEP. Above all, an improved ventilation-perfusion ratio within separately ventilated units can be achieved (23). 


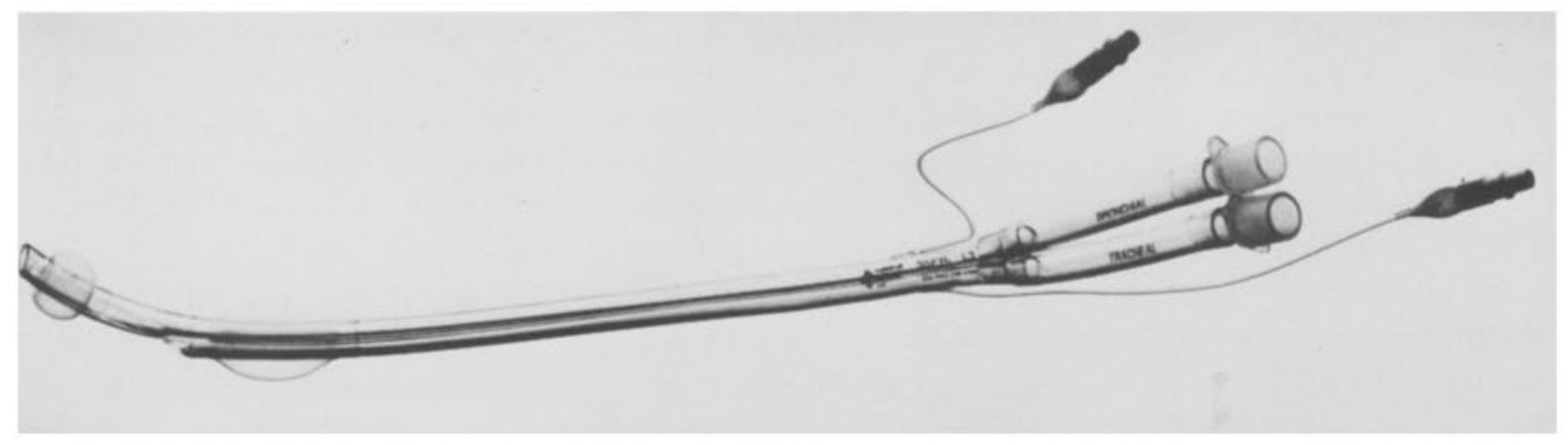

Fig. 1. The double-lumen bronchial catheter with high-volume, low-pressure cuffs (Broncho-Cath, National Catheter Co) used in the cases reported here.

\section{Procedure for differential ventilation}

The prerequisites for clinical use of differential ventilaton and selective PEEP are:

1) An inequality in pathological state between the two lungs, or, in the case of homogeneous lung disease, lateral decubital positioning of the patient.

2) selective main bronchial intubation; and

3) the availability of two seperate gas delivering sources.

In the case of unilateral lung disease the ventilatory method described below can be carried out while the patient is in the supine position. This has previously been described by other authors $(1,2,24$, 25).

The vast majority of patients in ARF, however, do suffer from lung disease with bilateral involvement. In order to administer differential ventilation in these patients they must be positioned in one of the two possible strictly lateral decubital postures. The lateral position is commonly used in the intensive care unit (ICU) and a rotating scheme with the patient being placed alternatively on his right and left side is followed to prevent bedsores and to improve the elimination of airway secretions. In these patients the differential ventilation method can be integrated into the routine care. The volume supplied to each lung and the selective PEEP to the dependent lung can thus be altered at the same time as the patient is moved from one side to the other.
Selective main bronchial intubation can easily be performed by any experienced anaesthetist or intensive care physician by using the same technique as for normal orotracheal intubation. We have used a disposable double-lumen catheter of soft plastic and with high-volume, low-pressure cuffs (Broncho-Cath, National Catheter Co.) (Fig. 1). The predecessor of this tube, the so-called 'Carlens' tube, is equipped with a small 'hook' so that it can be hooked on the carina, thus facilitating its positioning. This hook is not present on the Broncho-Cath, but as an aid in positioning of the tube a suction catheter can be inserted into the proximal (tracheal) side hole of the tube (see Fig. 1). When the tube is in position the suction catheter is simply removed. After inflation of the two cuffs, the position of the double-lumen tube can be grossly checked by inflating each lung separately while auscultating the breath sounds over each lung. To further check the tightness of the airway system, we suggest that a small balloon be fitted to one of the two openings of the tube and ventilation be administered only through the other. Inflation-deflation of the balloon in phase with the ventilation of the contralateral lung, with no progressive increase in residual balloon volume, indicates a tight airway system. This check should be made at regular intervals and especially when the patient's position has been altered.

A check for satisfactory lung separation can also be made as follows: One lung is ventilated at a PEEP of $5 \mathrm{~cm} \mathrm{H}_{2} \mathrm{O}$, while the tube from the other 
lung is immersed in water; if no air bubbling is seen, satisfactory lung separation has been established. The patient has to be heavily sedated and should not be allowed to cough on the tube or to move his head.

The Broncho-Cath with its two air chanels has a slightly higher resistance to the air stream than the conventional single-lumen tube. This has been of no practical importance, however, in our patients. Furthermore, the resistance is almost equally high in the two air channels.

A question that has been raised by many colleagues is whether we do not have problems with removing mucous secretions while using the double-lumen tube with its narrow air channels. Many of our patients have had abundant mucus produc- tion due to infectious lung disease and the removal of these secretions has actualy been facilitated by the double-lumen intubation. The reason is that the double-lumen tube together with the lateral posture permits removal of airway secretions from the non-dependent lung (in the drainage position), while ventilation is administered uninterruptedly, in the well-perfused dependent lung. Moreover, suctioning of one lung at a time reduces the risk of hypoxaemia induced by suctioning itself. However, an extra long suction catheter has to be used, and care must be taken to pass it through the entire length of the tube. This can be facilitated by wetting the catheter with saline before introducing it into the tube.

In our short-term studies $(6,7,26)$ and in our few

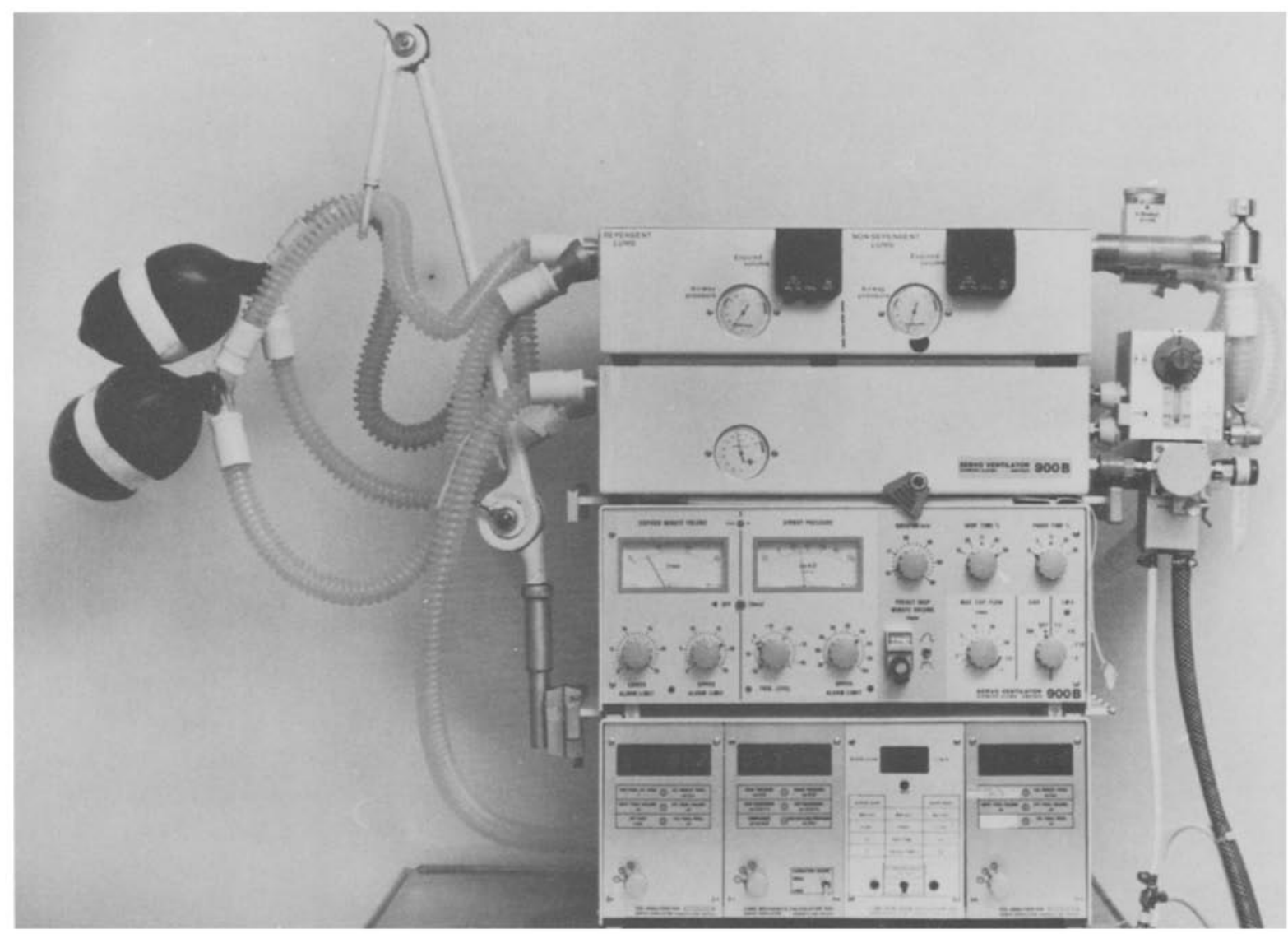

Fig. 2. Front view of the flow-dividing unit on top of the Servo ventiltor $900 \mathrm{~B}$ (Siemens Elema Co). This unit, which is a system of unidirectional valves and PEEP valves, permits the administration of differential ventilation and selective PEEP with one ventilator only. 
cases of long-term differential ventilation (27) the ventilation procedure has been accomplished with the aid of two synchronized ventilators (Servoventilator $900 \mathrm{~B}$ Siemens-Elema). The ventilators were electronically synchronized in such a way that the start of an inspiration was simultaneous for the two lungs. One of the ventilators (Master) controlled the other (Slave). This set-up permits individual adjustment of the tidal volume and end-expiratory pressure to each lung. In our experience, equal partitioning of the tidal volume between the dependent and non-dependent lung should be achieved. Selective PEEP of at least $1 \mathrm{kPa}$ to the dependent lung should be applied.

In parallel with the development and evaluation of differential ventilaton, a flow-dividing unit has been developed (Fig. 2). This device, which consists of a system of unidirectional valves and PEEP valves, permits differential ventilation with one ventilator only. The unit has been tested on in model and animal experiments and found to function satisfactorily (28).

\section{Two cases of long-term differential ventilation are presented in the following}

Case 1. A 71-year-old man underwent an emergency laparotomy (day 0 ) for peritonitis. The acute condition had been preceded by two weeks of fever and was complicated by ARF due to spreading atelectasis. He was transferred to ICU since he required artifical ventilation (AV) the night before the operation. Laparotomy revealed a severely inflamed gallbladder containing multiple stones, and cholecystectomy was performed and necrotic parts of the pancreas were removed. With several drains to the pancreatic region he was returned to the ICU, still requiring $\mathrm{AV}$ with an inspired oxygen fraction $\left(\mathrm{FiO}_{2}\right)$ of 0.70 (Fig. 3). A kidney infection superimposed, and pulmonary X-ray showed atelectasis, bilateral pneumonia and pleural effusion. A pulmonary artery themodilution catheter was inserted on day 3, and PEEP was applied. In view of the circulatory instability and the PEEP requirement of $1.2-1.7 \mathrm{kPa}$, it was decided to institute differential ventilation with selective PEEP

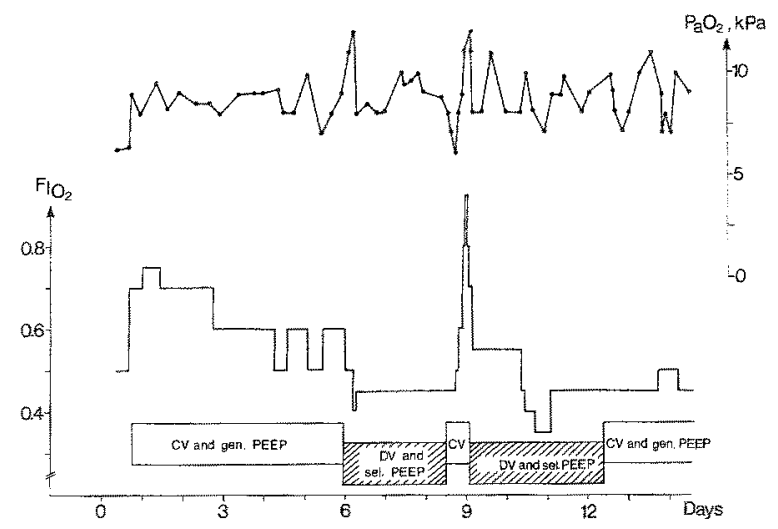

Fig. 3. Case 1. Inspired oxygen fraction $\left(\mathrm{FiO}_{2}\right)$ and arterial oxygen tension $\left(\mathrm{PaO}_{2}\right)$ during conventional ventilation (CV) and differential ventilation with selective PEEP (DV and sel. PEEP).

(DV) on day 5. A double-lumen bronchial catheter was inserted and the patient was connected to two synchronized ventilators and placed in the lateral decubital position. Half of the tidal volume was given to each lung, adding up to a total minute ventilation of 11-121. The respiratory frequency was $14 / \mathrm{min}$. The patient was kept constantly in one of the lateral decubital positions and was turned every third hour from side to side. Selective PEEP of 1.5-1.7 kPa was given to the dependent lung and of $0.5-0.7 \mathrm{kPa}$ to the non-dependent lung. A PEEP difference of $1.0 \mathrm{kPa}$ between the lungs was chosen on the basis of previous findings $(7,26)$. However, we did not initially withdraw PEEP completely from the non-dependent lung, as the patient was relatively hypervolaemic. This was a result of the demand for high volume loading during the previous period of conventional ventilation $(\mathrm{CV})$ with high general PEEP for maintenance of a reasonable systemic blood pressure. Cardiac output, as measured by thermodilution, increased slightly after the start of DV. But, more importantly, $\mathrm{FiO}_{2}$ could be reduced to 0.45 , with maintenance of an adequate arterial oxygen tension $\left(\mathrm{PaO}_{2}\right)$ (Fig. 3). After 3 days of DV the general condition had improved. However, the patient still required ventilatory support and a tracheostomy was performed. As no double-lumen tracheostomy tube was avail able, an ordinary tracheostomy tube was inserted on day 8 and $\mathrm{CV}$ was instituted. However, during 
the following $8 \mathrm{~h}$ the blood gases deteriorated progressively, and finally $\mathrm{PaO}_{2}$ was only $8 \mathrm{kPa}$ despite an $\mathrm{FiO}_{2}$ of 0.80 and a general PEEP of $1.5 \mathrm{kPa}$ (Fig. 3). This contrasted sharply to the situation earlier on the same day on $\mathrm{DV}$, with $\mathrm{PaO}_{2}$ of $9 \mathrm{kPa}$ at an $\mathrm{FiO}_{2}$ of 0.45 . Once again the patient was orally intubated with a double-lumen catheter, placed in the lateral position and given DV. In less than $6 \mathrm{~h} \mathrm{FiO}_{2}$ could be reduced to 0.55 with maintenance of $\mathrm{PaO}_{2}$ at $8 \mathrm{kPa}$ (Fig. 3). On postoperative day 12, after another 3.5 days on DV, a further attempt was made to re-institute $\mathrm{CV}$. The patient was placed in the supine position, with a general PEEP (both lungs) of $1.2 \mathrm{kPa}$. He was still ventilated through the double-lumen tube in case DV had to be recommenced. After $20 \mathrm{~h}$ on $\mathrm{CV}$ with monitoring of blood gases, a tracheostomy was once again performed and $\mathrm{CV}$ was continued. Again a definite but much less pronounced deterioration in oxygenation was seen after a changeover from DV to CV. The patient was succesfully weaned from the ventilator on day 35 and finally recovered. He was discharged from hospital 2 months later.

Case 2. A 47-yearmold man was transferred to the ICU with ARF. Four weeks earlier he had been admitted to the hospital with a newly diagnosed promyelocytic leukaemia. He received aggressive chemotherapy and massive plasma and platelet transfusions. Pulmonary $\mathrm{X}$-ray showed bilateral pneumonia.

$\mathrm{He}$ was intubated and given $\mathrm{CV}$ with general PEEP of $1.0 \mathrm{kPa}$. $\mathrm{FiO}_{2}$ had to be rapidly increased to 1.0 the same day, resulting in $\mathrm{PaO}_{2}$ of only $8 \mathrm{kPa}$. In the following two days on $\mathrm{CV}$, some improvement of oxygenation was seen with high PEEP, but pulmonary $\mathrm{X}$-ray showed progression of infiltrates. His condition deteriorated on day 4 , with a $\mathrm{PaO}_{2}$ of only $5 \mathrm{kPa}$ in spite of general PEEP of $1.0-1.5 \mathrm{kPa}$ and $\mathrm{FiO}_{2}$ of 0.90 (Fig. 4). DV was instituted, since remission of the leukaemia was considered still possible. Following double-lumen intubation, his oxygenation displayed an immediate improvement which lasted through the next $24 \mathrm{~h}$ enabling us to lower $\mathrm{FiO}_{2}$ to 0.75 with $\mathrm{PaO}_{2}$ above $8 \mathrm{kPa}$ (Fig. 4). The selective PEEP to the dependent lung was kept at $1.5 \mathrm{kPa}$ while the non-dependent lung was

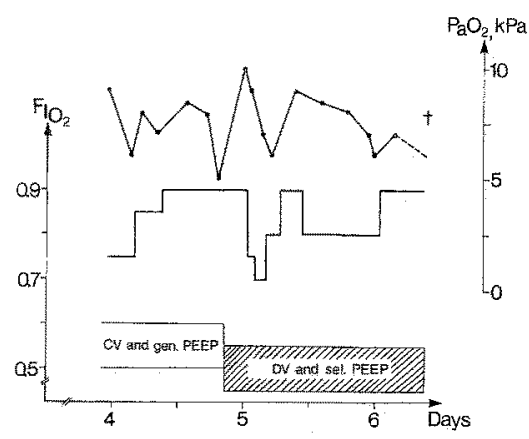

Fig. 4. Case 2. Inspired oxygen fraction $\left(\mathrm{FiO}_{2}\right)$ and arterial oxygen tension $\left(\mathrm{PaO}_{2}\right)$ during conventional ventilation $(\mathrm{CV})$ and differential ventilation with selective PEEP (DV and sel. PEEP) from the third day of admission to the intensive care unit.

ventilated without PEEP throughout the whole period of DV. However, pulmonary X-ray showed worsening of the lung condition, with progressive pneumonic infiltrates, and oxygenation again started to decline. He died (day 6) after 36 h of DV hypoxaemia and heart failure. A post-mortem examination showed totally hepaticized lungs with several areas of bleeding. Microscopy revealed hyaline membranes, atelectasis and mycotic invasion.

To conclude, we consider that perfusionmatched differential ventilation should be instituted when a hypoxaemia due to bilateral diffuse lung disease threatens to be complicated by oxygen toxicity. We therefore recommend this mode of ventilatory support if a patient is receiving an $\mathrm{FiO}_{2}>0.50$ for more than $48 \mathrm{~h}$ with a $\mathrm{PaO}_{2}<10 \mathrm{pKa}$, irrespective of what PEEP level is tried.

We believe, furthermore, that after additional clinical studies DV will gradually attain a much broader set of indications in the ICU and surgical wards, owing to its positive effects on cardiac output, and shunting, and its prophylactic capacity againts the development of atelectasis in dependent lung regions.

\section{Acknowledgements}

This study was supported by grants from the Swedish Medical Research Council (No. 4X-5315), 
the Laerdal Foundation for Acute Medicine, the Karolinska Institute, The Siemens Elema Co and by a visiting scholarship from the Exchange Program between the Swedish and Polish Academies (M. Darowski).

\section{References}

1. Carlon GC, Kahn R, Howland WS, Baron R, Ramaker J: Acute life-threatening ventilation-perfusion inequality: An indication for independent lung ventilation. Crit Care Med 6: $380-383,1978$.

2. Westenskow DR, Pace NL: Differential lung ventilation. In: Prakash, O (ed): Applied physiology in clinical respiratory care. The Hague/Boston/Lancaster: Martinus Nijhoff Publishers, 1982.

3. Carlens $E$ : A new flexible double-lumen catheter for bronchospirometry. J Thorac Surg 18: 742-746, 1949.

4. Wood RE, Campbell D, Razzuk MA: Surgical advantages of selective unilateral ventilation. Ann Thorac Surg: 173$180,1972$.

5. Hedenstierna G, Santesson J, Bindslev L, Baehrendtz S, Klingstedt $\mathrm{C}$, Norlander $\mathrm{O}$ : Regional differences in lung function during anaesthesia and intensive care: clinical implications. Acta Anaesth Scand 26: 429-434, 1982.

6. Baehrendtz S, Santesson J, Bindslev L, Hedenstierna G, Matell $G$ : Differential ventilation in acute bilateral lung disease. Influence on gas exchange and central haemodynamics. Acta Anesthesiol Scan 27: 270-277, $1983 a$.

7. Baehrendtz S, Bindslev L, Hedenstierna G, Santesson J: Selective PEEP in acute bilateral lung disease. Effect on patients in the lateral posture. Acta Anaesthesiol Scand 27: 311-317, 1983b.

8. Kanarek DJ, Shannon DC: Adverse effects of positive endexpiratory pressure on pulmonary perfusion and arterial oxygenation. Am Rev of Resp Dis 112: 457-459, 1975.

9. Zack MB, Pontoppidan H, Kazemi H: The effect of lateral positions on gas exchange in pulmonary disease. Am Rev of Resp Dis 110: 49-55, 1974.

10. Ibanez J, Raurich JN, Abizanda R, Claramonte R, Ibanez $P$, Bergada J: The effect of lateral positions on gas exchange in patients with unilateral lung disease during mechanical ventilation. Intensive Care Med 7: 231-234, 1981.

11. Alfery DD, Zamost BG, Benumof JL: Unilateral lung lavage: Blood flow manipulation by ipsilateral pulmonary artery ballon inflation in dogs. Anesthesiology 55: 376-380, 1981.

12. Katz JA, Ozanne GM, Zinn SE, Fairley HB: Time-course and mechanisms of lung-volume increase with PEEP in acute pulmonary failure. Anesthesiology 54: 9-16, 1981.
13. Milic-Emili $J$, Henderson JAM, Dolovitch MB, Trop D, Kaneko K: Regional distribution of inspired gas in the lung. J Appl Physiol 21: 749-759, 1966.

14. Pontoppidan H, Geffin B, Lowenstein E: Acute respiratory failure in the adult. N Engl J 287: 690-698, 1972.

15. West JB: Regional differences in gas exchange in the lung of erect man. J Appl Physiol 17: 893-898, 1962.

16. Asbaugh DG, Petty TL, Bigelow DB, Harris TM: Continuous positive pressure breathing in adult respiratory distress syndrome. J thorac cardiovasc Surg 57: 31-41, 1969.

17. Kumar A, Falke KJ, Geffin B, Aldredge CF, Laver MB, Lowenstein $\mathrm{E}$, Pontoppidan $\mathrm{H}$ : Continuous positive pressure ventilation in acute respiratory failure. Effects on hemodynamics and lung function. N Engl J Med 238: 1430 $1436,1970$.

18. Bindslev L, Santesson J, Hedenstierna G: Distribution of inspired gas to each lung in anaesthetized human subjects. Acta Anaesthesiol Scand 25: 297-302, 1981.

19. Colgan FJ, Barrow RE, Fanning GL: Constant positive pressure breathing and cardiorespiratory function. Anesthesiology 34: 145-151, 1971.

20. West JB, Dollery CT, Naimark A: Distribution of blood flow in isolated lung: Relation to vascular and alveolar pressure. J Appl Physiol 19: 713-724, 1964.

21. Bindslev L, Hedenstierna G, Santesson J, Norlander O, Gram I: Airway closure during anaesthesia and its prevention by positive end-expiratory pressure. Acta Anaesthesiol Scand 24: 199-205, 1980.

22. Kumar A, Pontoppidan H, Falke K, Wilson R, Laver MB: Pulmonary barotrauma during mechanical ventilation. Crit Care Med 1: 181-186, 1973.

23. Bachrendtz S, Hedenstiena G, Santesson J, Bindslev L, Klingstedt $C$, Dahlborn $M$, Söderborg $B$, Norlander OP: Perfusion of each lung during differential ventilation with selective PEEP. Anesthesiology 57: Abstract 458, 1982.

24. Glass DD, Tonnesen AS, Gabel JC, Arens JF: Therapy of unilateral pulmonary insufficiency with a double-lumen endo-tracheal tube. Crit Care Med 4: 323-326, 1976.

25. Powner DJ, Eross B, Grenvik $\AA$ : Differential lung ventilation with PEEP in the treatment of unilateral pneumonia. Crit Care Med 5: 170-172, 1977.

26. Baehrendtz S, Klingstedt C: Differential ventilation and selective PEEP during anaesthesia in the lateral decubital posture. Acta Anaesthesiol Scand, 1983, in press.

27. Frostell C, Blomqvist $H$, Nilsson JA, Grenrot C, Baehrendtz S, Hedenstierna $G$ : Perfusion-matched differential ventilation with selective PEEP in bilateral lung disease. To be published.

28. Darowski $M$, Hedenstierna $G$, Baehrendtz S: Differential ventilation and selective PEEP with one-power source (ventilator principles and model tests). To be published.

Accepted: March 19, 1984 